\title{
Relationship Between Facebook Problematic use and Pathological Personality Traits: a Systematic Review
}

\author{
Bárbara Letícia Ferrari ${ }^{1}$ \\ Lucas de Francisco Carvalho ${ }^{1}$ \\ Catarina Possenti Sette ${ }^{1}$ \\ ${ }^{1}$ Universidade São Francisco, Campinas, São Paulo, Brasil
}

\begin{abstract}
We aimed to investigate relationships between Facebook problematic use (Facebook PU) and pathological traits of personality, by a systematic review. The literature search was proceeded based on a search strategy including the keywords "Facebook", "problematic use" and "personality". We found a total of 236 publications and selected 21 papers for full verification. All of them were excluded, characterizing an empty review. As an attempt to increase the probability of finding eligible publications, first, we have broadened the search of the systematic review from "Facebook" to "social network sites" (and variations); and then from "social network sites" to "internet". Regarding this last change, the final set of publications after full reading based on the eligibility criteria was composed by 15 papers. We emphasize that there was no empirical evidence on the relationship between Facebook PU and pathological traits of personality. Given the proximity between Facebook PU and internet addiction, it is possible to hypothesize that there is a relationship between pathological traits (i.e., Neuroticism, Impulsivity, and Psychoticism) and Facebook PU.
\end{abstract}

Keywords: personality disorder; internet (addiction); nonchemical dependency; literature review.

Relação Entre uso Problemático do Facebook e Traços Patológicos da Personalidade: uma Revisão Sistemática

\section{Resumo}

O objetivo desse estudo foi investigar as relações entre o uso problemático do Facebook (Facebook PU) e traços patológicos, por meio de uma revisão sistemática. Os descritores foram "Facebook", "uso problemático" e "personalidade", e variações foram incluídas. Foi encontrado um total de 236 publicações. Entre elas, 21 foram selecionadas para leitura completa e todas foram excluídas, o que caracterizou o trabalho como uma empty review. Como uma tentativa de aumentar a probabilidade de encontrar publicações elegíveis, foi ampliado a busca para "internet”. O conjunto final de publicações após a leitura completa com base nos critérios de elegibilidade foi composto por 15 artigos. Ressalta-se que não há evidência empírica sobre a relação entre o Facebook PU e traços patológicos. Dada a proximidade entre o Facebook PU e a dependência da internet, é possível supor que existe uma relação entre traços patológicos (isto é, neuroticismo, impulsividade e psicoticismo) e o Facebook PU.

Palavras-chave: distúrbios da personalidade, dependência não química, internet (dependência), revisão de literatura.

\section{Relación Entre uso Problemático de Facebook y Características Patológicos de la Personalidad: una Revisión Sistemática}

\section{Resumen}

El objetivo de este estudio fue investigar las relaciones entre el uso problemático de Facebook (Facebook PU) y los rasgos patológicos de la personalidad, a través de una revisión sistemática. La búsqueda bibliográfica incluyó los descriptores "Facebook", "uso problemático", "personalidad” y variaciones. Se encontró un total de 236 publicaciones, de las cuales, 21 fueron seleccionadas para la verificación completa, a pesar de que todos fueron excluidos, lo que caracterizó el trabajo como una revisión vacía. En un intento de aumentar la probabilidad de encontrar publicaciones elegibles, se amplió las palabras claves a "sitios de redes sociales" (y variaciones); y luego a "internet". El conjunto final de publicaciones después de la lectura completa basada en los criterios de elegibilidad consistió en 15 artículos. Cabe enfatizar que no hubo evidencias empíricas sobre la relación entre el Facebook PU y los rasgos patológicos. Dada la proximidad entre Facebook PU y la adicción a Internet, es posible suponer que existe una relación entre los rasgos patológicos (i.e., neuroticismo, impulsividad y psicoticismo) y Facebook PU. Palabras clave: trastorno de personalidad; internet (adicción); dependencia no química; revisión de literatura.

\section{Introduction}

Facebook is a social networking site (SNS) characterized by providing several features for social interaction and is often used daily by its users (Mahajan, 2009). Some people may find it difficult to monitor the time spent on this SNS. Intense access to the platform can lead to interpersonal, social, and professional problems, as the individual stops doing other activities or interacting personally with others to be connected to the Facebook (Blachnio et al., 2017; Elphinston \& Noller, 2011; Lee et al., 2012). Studies are reporting that users wake up in the middle of the night to check on social media (Abhijit, 2012) and that there are individuals who 
are more interested in being connected to SNSs than sleeping and resting (Hofmann et al., 2012). Furthermore, there is a growing complaint in mental health services regarding the increase of social isolation due to the excessive use of the platform (Guedes et al., 2016). Such behaviors may be called Facebook problematic use (Facebook PU) (Blachnio et al., 2017; Elphinston \& Noller 2011).

Previous studies suggest personality traits as relevant predictors of the Facebook PU. For instance, Marino et al. (2016) found a direct relationship between Facebook PU and extraversion, and indirectly (through motives and metacognitions) relationship between Facebook PU and emotional stability. Moreover, there are studies suggesting the relationship between pathological traits of personality and Facebook non-PU. Kapidzi (2013) found that people with typical symptoms of Narcissistic Personality Disorder (NPD) are highly motivated to show their positive features on Facebook, in addition to having more markups, photos, status updates and more time spent on Facebook. Significant correlations were observed between histrionic PD (HPD) symptoms and Facebook non-PU, as well as a tendency to present a higher number of friends compared to non-HPD people (Rosen et al., 2013). This evidences suggest possible relationships between pathological personality traits (and PDs) and Facebook PU.

\section{Rationale and aims of the current systematic review}

Considering previous evidence linking personality traits and Facebook PU (e.g., Marino et al., 2016), and also taking into account that there is evidence relating pathological personality traits and Facebook non-PU variables (e.g., Kapidzi, 2013, Mehdizadeh, 2010; Rosen et al., 2013), our hypothesis is that there is a positive relationship between Facebook PU and pathological personality traits (and PDs). The present study aimed to investigate the relationship between Facebook PU and pathological personality traits/PDs. A systematic review was carried out.

\section{Materials and Methods}

The procedures used in this study were performed based on PRISMA guideline suggested for conducting a systematic review (Moher et al., 2009).

\subsection{Search Strategy}

As a first step, we conducted a screening in March 2017. We searched the PsyInfo, PubMed, and Science Direct databases, focusing on peer-reviewed journals.
The selected terms were grouped (i.e., Boolean operator AND) into three sets: (1) Facebook, Internet and social network site, online social network; (2) dependence/ dependency, problematic use, abusive use, addiction; (3) personality disorder, pathological personality trait, pathological personality. Variations of these terms (e.g., Facebook dependence, abusive use, inadequate personality) were used, based on the MeSH mechanism of PubMed. We entered these terms in the title, abstracts, keywords and full texts. Complementarily, we also hand searched at Google Scholar, the first 10 pages.

\subsection{Eligibility Criteria}

As a second step, we conducted a screening of the title and abstract of each paper selected from the search strategy. We include studies that (1) provided empirical evidences of the relation between Facebook problematic use/addiction and pathological personality traits, (2) involved adults aged 18 or older, and (3) included a measurement of Facebook problematic use or addiction, and a measurement of personality disorders or pathological personality traits. We used no restrictions of date and language. We excluded studies that (1) evaluated aspects of the Facebook not directly related to problematic use or addiction (e.g., general use, motivations) and/or (2) included only Facebook assessment or pathological personality traits assessment.

\subsection{Data Extraction}

Data were extracted using a standardized data extraction method by the authors. Paper managing was conducted using Mendeley Desktop version 1.16.1 for Windows. We distributed the papers in folders depending on database, then, duplicate papers verification was proceeded. Two authors independently assessed titles and abstracts to select papers within the established inclusion criteria. Discrepancies were solved by consensus, considering a third author. Then, the authors read the selected articles, focusing mainly on the Method and Results, considering the established inclusion criteria. From this more detailed reading, the selected papers met the criteria for inclusion in the systematic review.

\subsection{Quality report and bias risk assessment}

As we did not find specific tools for quality report assessment and bias risk, we integrated parts of tools and strategies used in previously research. For quality report assessment: Strengthening the Reporting of Observational studies in Epidemiology (STROBE; von Elm et al., 2007); for bias risk: Critical Appraisal 
and Data Extraction for Systematic Reviews of Prediction Modeling Studies (CHARM; Moons et al., 2014) guidelines and some keys were created according to other researches. However, as can be observed in the results, as we did not find publications matching inclusion criteria, we could not apply the key items selected in these tools and the key items we planned to insert in the adapted tools. We are presenting the findings of this (empty) systematic review, following the procedures suggested in the previous literature (Lang et al., 2007; Moat et al., 2013; Schlosser \& Sigafoos, 2009; Slyer, 2016; Yaffe et al., 2012).

\section{Results}

\section{Study Selection}

Using the previously described criteria and databases, we identified 142 publications. The search using Google Scholar provided 94 additional publications. The correct amount identified, after removing for duplicates, was 236. In the screening stage, based on the reading of the titles and abstracts, most of the papers were excluded $(91,1 \%)$. The 21 remaining papers were fully verified, and all of them were excluded. In all cases, the exclusion in the final selection was by not using a measure assessing Facebook PU, some of the papers assessed Facebook but not problematic use $(n=2)$, and others were not focused on Facebook $(n=19)$. The result was, in the terminology of the systematic review methodology, an "empty review" (i.e., a systematic review in which no eligible study was identified (Lang et al., 2007). The detailed process can be visualized in Figure 1.

As noted in Figure 1, no eligible studies were found for this systematic review. Specifically, one of the criteria was not met by any of the papers, i.e., to present empirical data of Facebook PU. Although there is no specific guide to reporting empty reviews (Yaffe et al., 2012), following the suggestion of Lang et al. (2007), we are using a specific expression for the present situation: in the present review, there were no eligible studies found.

Faced with the absence of studies showing effects on the relationship between problematic use of

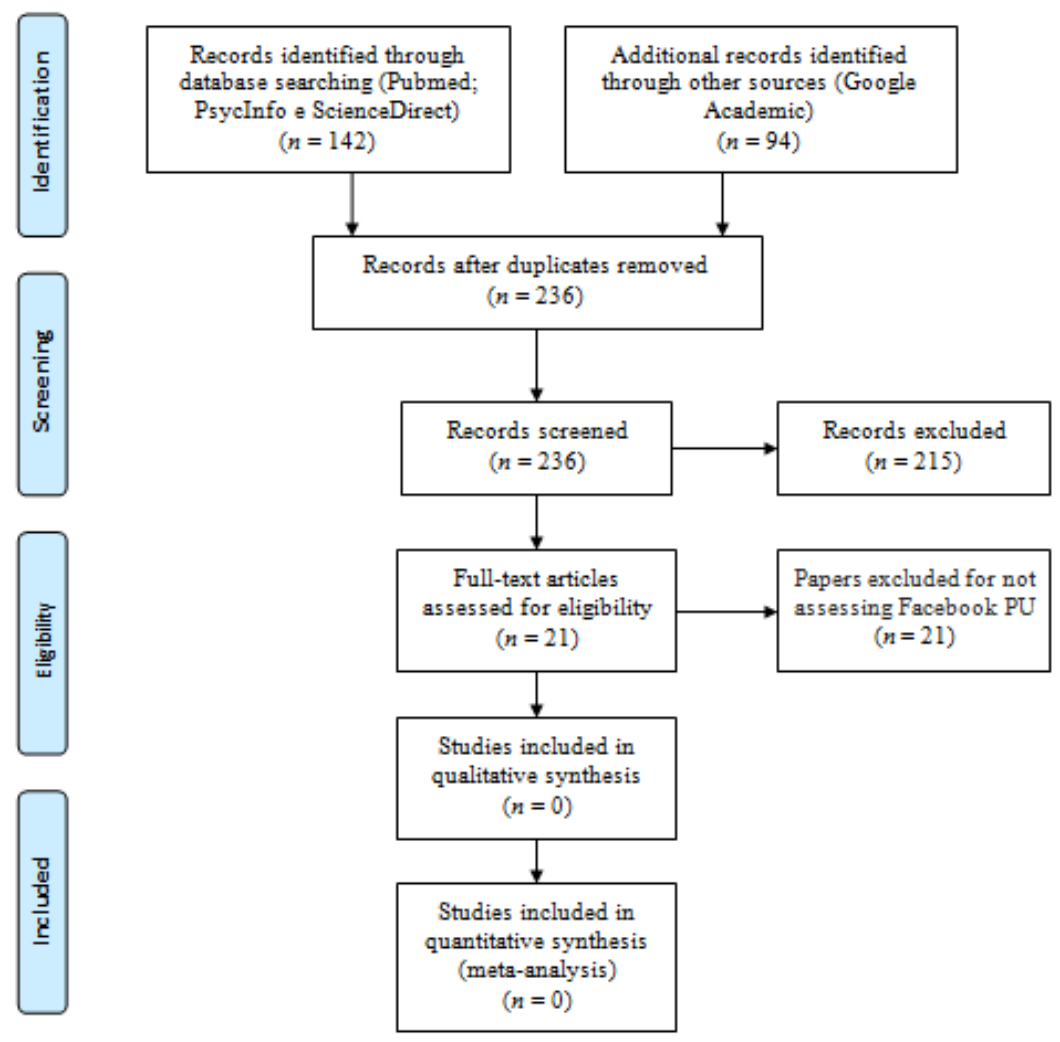

Figure 1. Flow diagram based on PRISMA. 
Facebook and pathological personality traits, our decision was to investigate peripheral studies as close as possible to our original goal. We tried not to conclude anything based on the absence of known effects (Yaffe et al., 2012), but to explore the broader field of study in which our goal is embedded. Furthermore, as suggested (Lang et al., 2007), we are presenting observations generated through the papers retrieved, even though none of them has met the initial eligibility criteria. Therefore, seeking to know the peripheral studies composing the broader field of study in which Facebook PU and pathological personality traits are inserted, we searched for papers presenting information regarding the relationship between internet problematic use/addiction and pathological personality traits. The terms used in the systematic review search procedure (e.g., Internet) made it possible to search for publications on Internet problematic use/addiction. We must highlight that previously we also looked at studies dealing with problematic use/addiction in other online social networks since the terms used allowed this verification (e.g., social network site, online social network), but no study was found.

Since the initial search terms enabled the verification of studies relating Internet problematic use/ addiction with pathological personality traits, we started with the 236 publications reported in Figure 1, whose titles and abstracts were read by two researchers independently. The same inclusion and exclusion criteria were used, but now replacing "Facebook" over "internet". We hand-searched Google Scholar again, the first 10 pages each time. After the titles and abstracts were screened, 39 publications were selected, which were read in full. One of the studies, despite meeting all inclusion criteria, presented no relevant results regarding the relationship between pathological personality traits/PDs and internet addiction, as the focus of the study was the bipolar disorder (Wölfling et al., 2015). So, we decided to exclude this paper, together with 20 studies that not reached all inclusion criteria. The final set of publications after full reading based on the eligibility criteria was composed of 15 papers.

\section{Study Characteristics}

For the results, we extracted the following data presents in Table 1 from the 15 studies.

More than three authors composed most studies $(n=13)$, and the number of authors ranged from two to nine. These authors $(n=65)$ were from several science fields, mainly from psychiatry (57\%), general medicine $(21.5 \%)$, and psychology (10.8\%). Almost all the authors were from health or health-related areas except four authors from the educational field. Maybe as reflection of it, publications were most in psychiatry journals $(n=8)$, followed by addiction-focused journals $(n=3)$, and human-computer interaction focused journals $(n=2)$. According, the more recurrent journal was Psychiatry Research $(n=3)$, followed by Journal of Behavior Addictions $(n=2)$, and Comprehensive Psychiatry $(n=2)$. Papers were published from 2009 to 2016, showing stability on the number of publications $(n=3)$ in the last years (i.e., 2014-2016). The sample's country also showed a tendency, being Taiwan the most frequent $(n=5)$ followed by Turkey and Germany $(n=$ 3 , each).

About $70 \%$ of the papers presented as focus one or more personality disorders or at least some pathological personality traits. In some of it $(n=4)$, the nosological diagnostic system (i.e., DSM-IV categorical) is clearly declared. PDs, in general, are encompassed in about one-third of the papers, and the borderline personality disorder is the focus on two publications. Neuroticism $(n=6)$, Impulsivity $(n$ $=5)$, and Psychoticism $(n=4)$ are the most frequent pathological personality traits investigated. In general, they were assessed by different measures, but the most recurrent was the Barratt Impulsiveness Scale (BIS-11; $n=2)$, the Symptom Checklist-90-R (SCL-90-R; $n=2)$, both self-report tools, and the Structured Clinical Interview for DSM-IV Axis II Disorders (SCID-II; $\mathrm{n}=2$ ), a structured interview. Only in one study a measure (i.e., NEO-FFI) based on the Five-Factor Model (FFM) was applied. Regarding the internet addiction measurement, all tools were self-report, mainly the Chinese Internet Addiction Scale (CIAS) and its revised version (CIAS$\mathrm{R})$, totaling five papers, the Scale for the Assessment of Internet and Computer Game Addiction (AICA-S; $n=3$ ), and the Internet Addiction Scale (IAS; $n=3$ ). These measurement tools were applied, in almost $70 \%$ $(n=11)$ of studies, to graduated or undergraduate students, in three papers to clinical patients, and in two papers, the specific group population was not presented in the paper. The sample size ranged from 50 to 4266 , seven studies composed by more than 500 subjects, and four studies composed of less than 200 subjects.

Altogether, the results reported in the studies indicated the relationship between IA and Neuroticism, Impulsivity, Psychoticism, and PDs. IA was positively correlated to Neuroticism (Chang et al., 2015; Dalbudak et al., 2014; Dong et al., 2012; Floros et al., 2014; Müller 


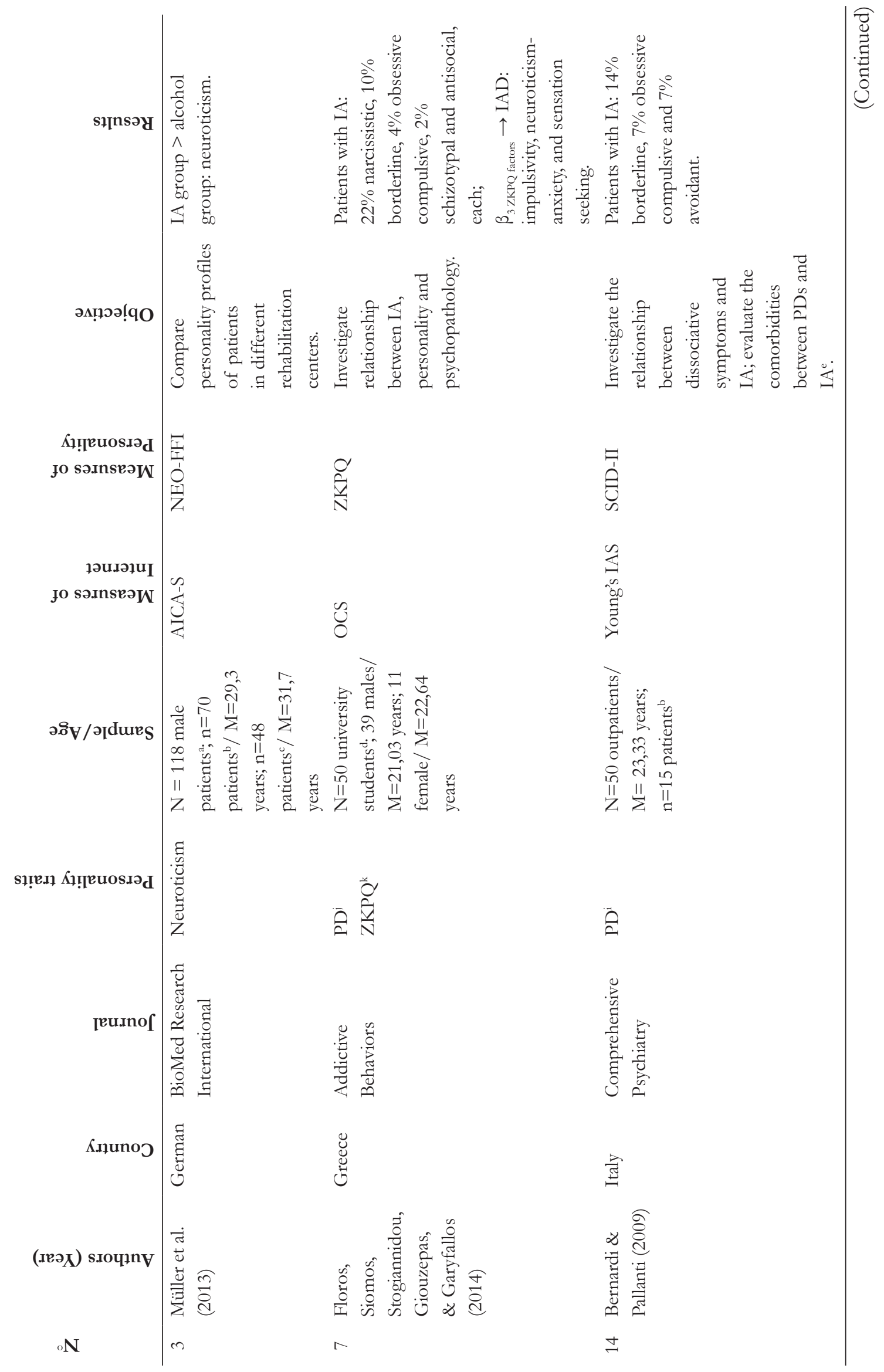




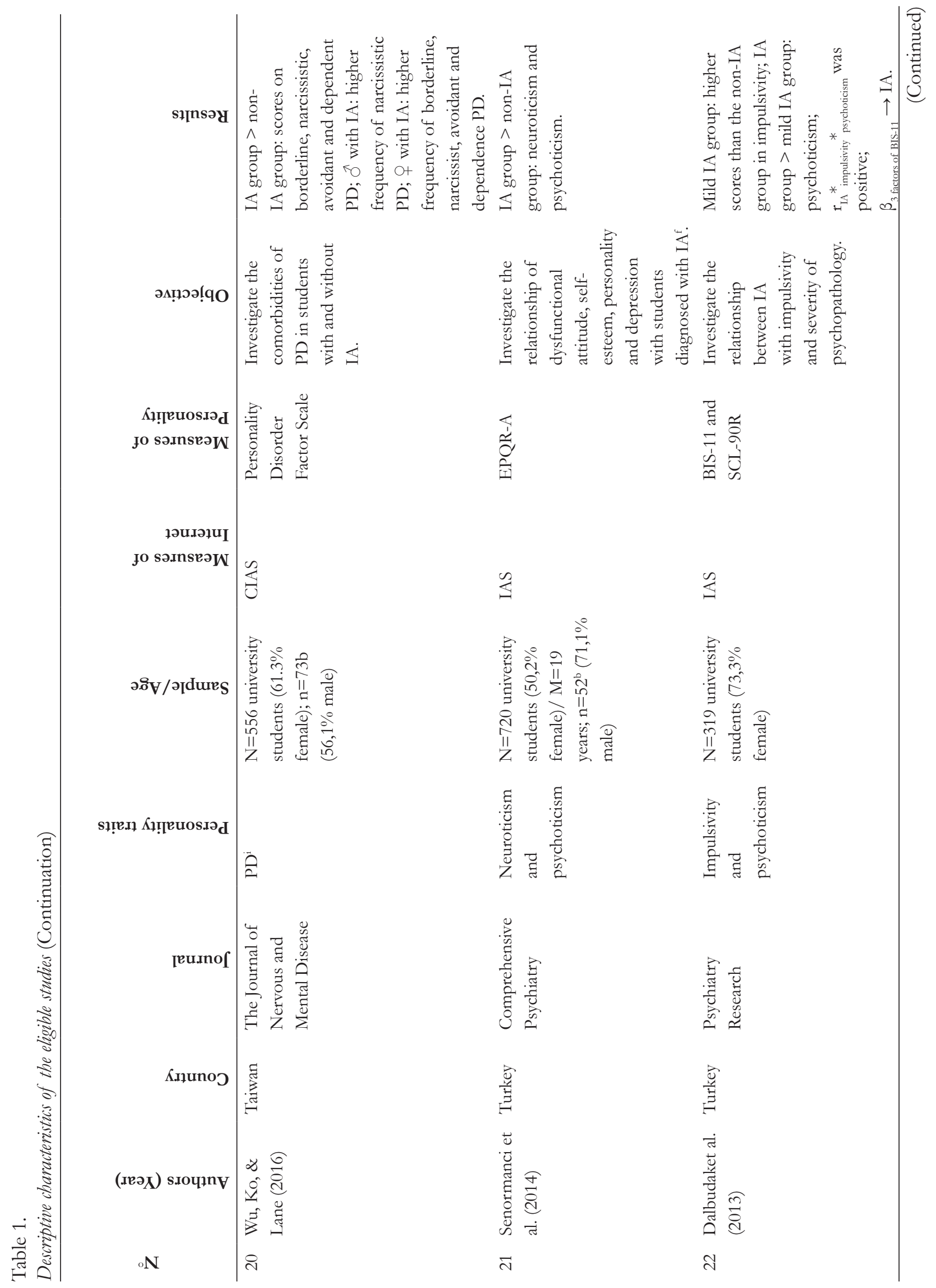




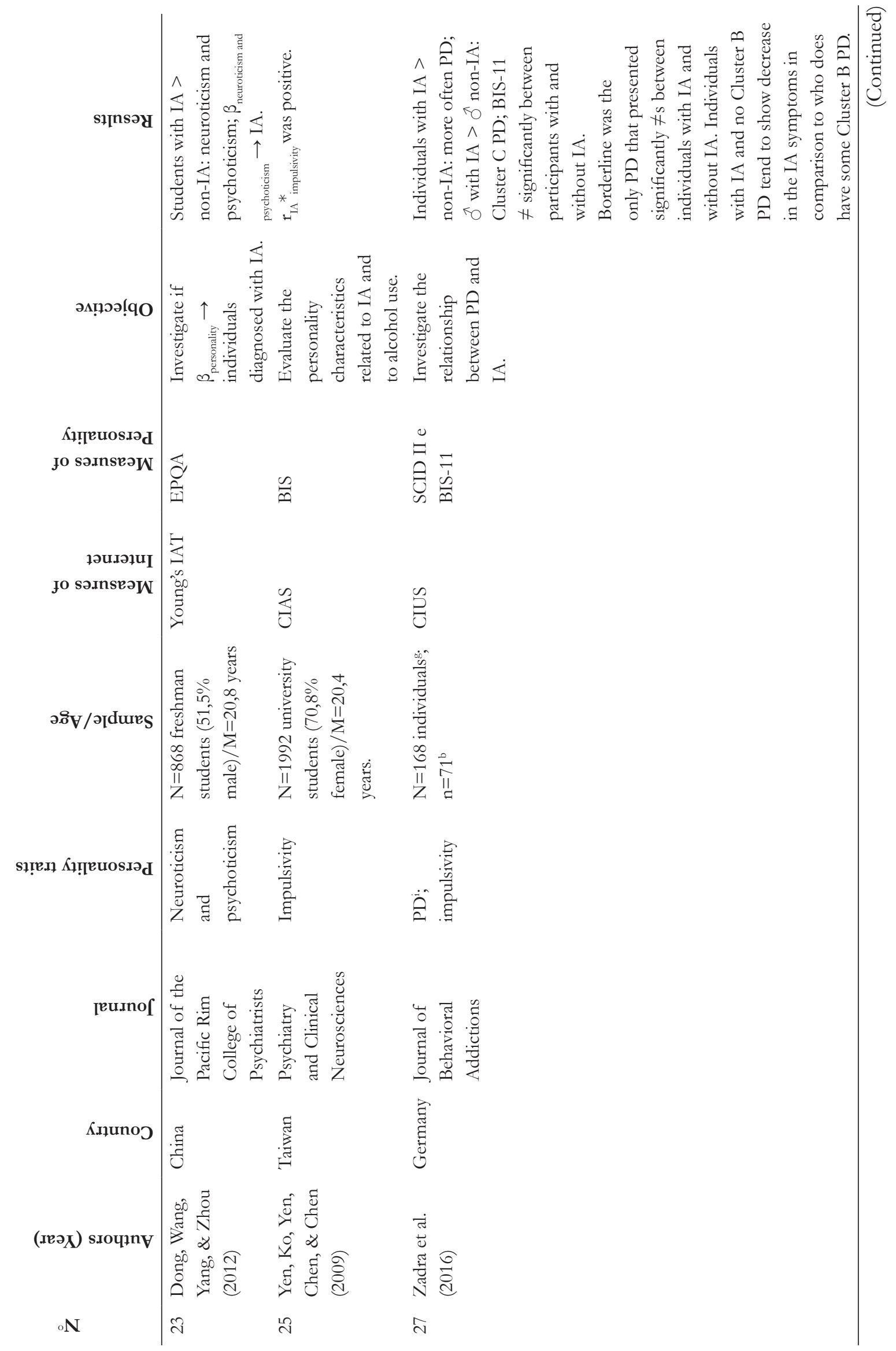




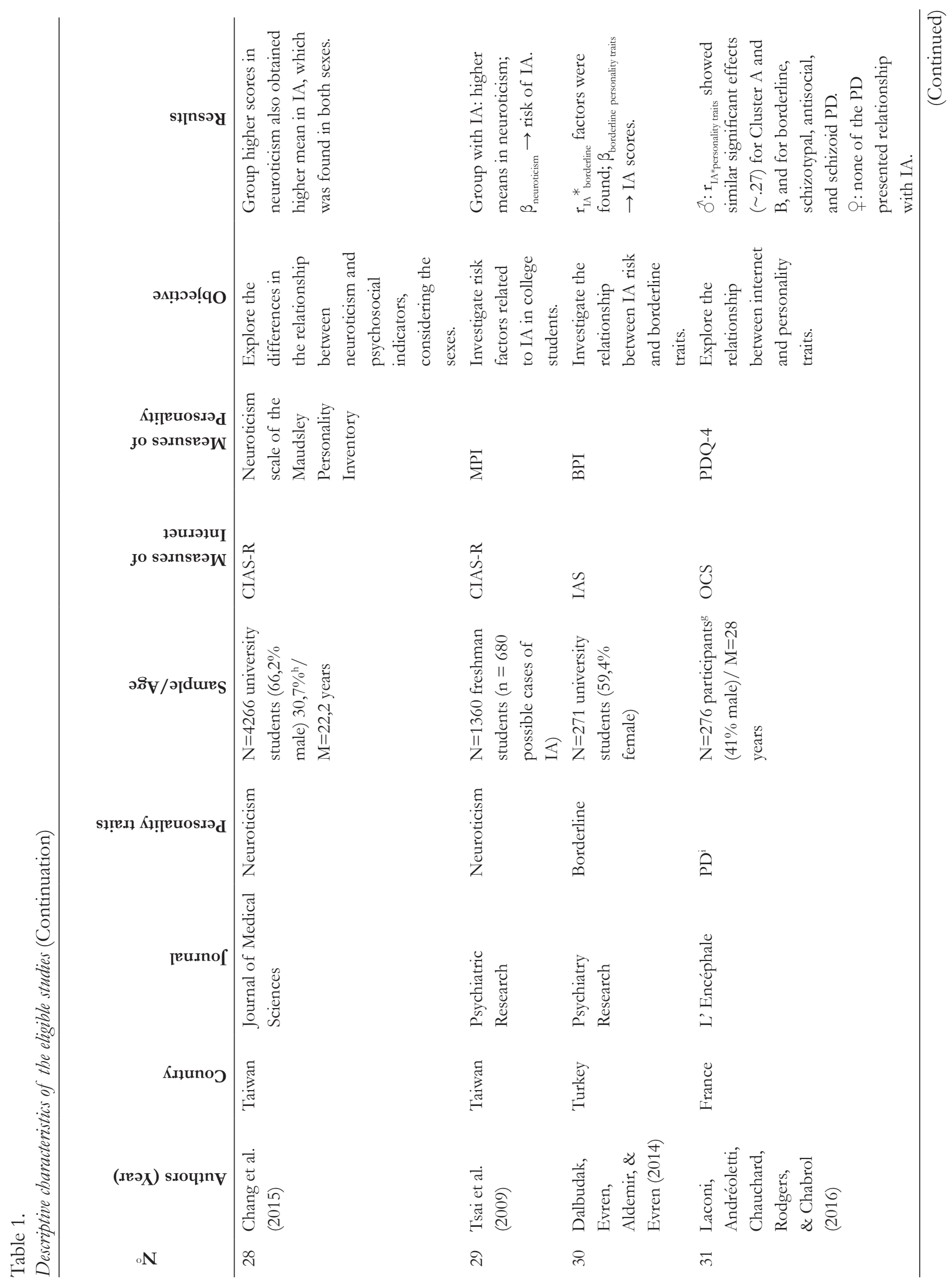



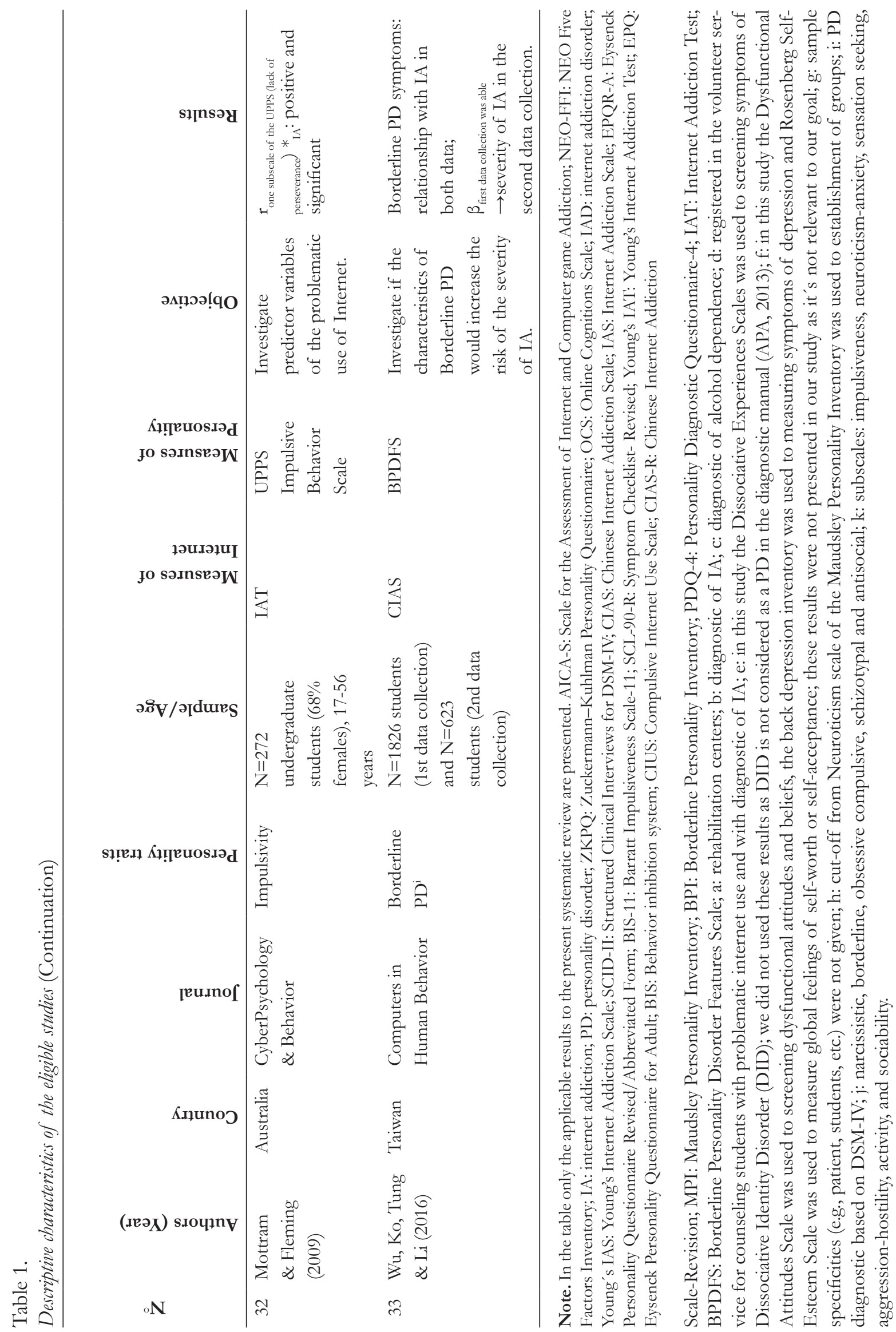
et al., 2013; Senormanci et al., 2014; Tsai et al., 2009), and this relationship does not change when controlling by sex (Chang et al., 2015). IA was also positively correlated to Impulsivity (Dalbudak et al., 2014; Floros et al., 2014; Mottram \& Fleming 2009; Zadra et al., 2016; Yen et al., 2009 - lack of perseverance), and Psychoticism (Dong et al., 2012; Senormanci et al., 2014). Moreover, PD presented a relationship with IA (Laconi et al., 2016; Zadra et al., 2016; Wu et al., 2016), but it seems to be mediated by the sex (e.g., Laconi et al., 2016). Borderline PD show up as one of the most related to IA (e.g., Dalbudak et al., 2014; Wu et al., 2015), the more prevalent (Bernardi \& Pallanti 2009; Wu et al., 2016; Zadra et al., 2016), and no sex differences were observed (Dalbudak et al., 2014). Contradicting these findings, in one study, no significant differences between the PD group and non-PD group was found (Floros et al., 2014).

\section{Discussion}

Based on previous findings (e.g., Kapidzi, 2013; Mehdizadeh, 2010; Rosen et al., 2013), our initial hypothesis was that the Facebook PU should be positively correlated to personality pathological traits/PDs in general. We performed the typical procedures of a systematic review. Considering the lack of studies according to our aim, this systematic review is characterized as an empty review (Lang et al., 2007). Empty reviews are rare, but maybe less than we usually think (Yaffe et al., 2012). Knowing that there is no evidence in support of or against a scientific problem based on the inclusion criteria used in the review is important, in terms of provide a clear direction for future original research (Schlosser \& Sigafoos, 2009).

Based on these premises, what the absence of evidence leads us to know concerning the initial objective of this systematic review? First, since there is no evidence in favor or against our hypothesis, it is not possible to state whether there is relationship between Facebook PU and pathological personality traits/PDs. However, the lack of evidence from an empty review is not an indication of lack of effect. Therefore, the main contribution of this study is to point out the necessity of empirical research showing the effects between the Facebook PU and pathological traits. It is surprising that almost 15 years after the Facebook was launched, and about 10 years after the first studies on Facebook relationship with personality traits was published, no study was published yet investigating the correlations between the addiction and other problematic uses of the most popular SNS and pathological variations of the personality traits.

As stated before, our decision was to investigate peripheral studies as close as possible to our original goal. We first looked at studies dealing with problematic use/addiction in any online social networks. But, again, no studies were found even relaxing the criteria to cover any SNS. Facing these results, we settle our search to the next natural broad field, i.e., internet problematic use/addiction relationship with pathological personality traits/PDs.

Regarding the characteristics of the selected publications, it was observed that most authors were from mental health departments, since these are publications dealing with two conditions: IA and pathological personality traits/PDs. Similarly, most of the journals were in the field of psychiatry. In addition, the country with more publications was Taiwan, which may be explained by the country's specific attention given to IA as a public health problem (Block, 2008). We also identified a larger number of publications in the last 5 years, suggesting that studies contemplating IA and pathological personality traits have been increasingly frequent, which is consistent with the widespread access to the Internet among the population (Ginige, 2017).

The studies' samples were predominantly composed by young, female, and university students. On the one hand, the majority of young people in the sample may be related to the public who use the Internet the most (e.g., Ginige, 2017), although the Internet has made it possible to include groups that are difficult to access in surveys (Onnela \& Rauch 2016). However, the observed trend may also denote the most represented group in behavioral sciences studies (i.e., Western, Educated, Industrialized, Rich, and Democratic; WEIRD). In this case, few studies sought to consider samples with psychiatric diagnoses, which may decrease variability regarding the variables investigated, since they represent atypical behaviors in the general population.

The most studied traits in the selected studies was Neuroticism, followed by Impulsivity and Psychoticism. The choice to investigate these traits with IA seems to have different reasons. Studies have shown that people with high scores in Neuroticism tend to use the Internet to soothe the loneliness generated by anxiety, shyness and insecurity, besides considering it a safe and comfortable environment (Butt \& Phillips, 2008; McCrae et al., 2002; Müller et al., 2013). Regarding Impulsivity, from the very nature of the trait it is possible to sustain its investigation with IA, since those who are 
prone to IA behaviors tend to make decisions without worrying about the consequences (Belin et al., 2008). Moreover, these people tend to see the Internet as an area in which they receive short-term rewards, and this immediate gratification tends to reinforce the use (Lee et al., 2012; Mazhari, 2012). Similarly, the association of IA with Psychoticism is related to the search for sensations, low impulse control, aggressiveness, insensitivity and socially unacceptable behaviors (e.g., Dalbudak \& Evren, 2014; Dong et al., 2012; Mok et al., 2014).

In general, Neuroticism (Dong et al., 2012; Floros et al., 2014; Tsai et al., 2009), Impulsivity (Dalbudak et al., 2013; Floros et al., 2014) and Psychoticism (Dong et al., 2012) were significant predictors of IA. Moreover, in group comparisons with college students, groups composed by people with high scores in IA obtained higher means in these pathological personality traits when compared with groups with low scores in IA (Chang et al., 2015; Senormanci et al., 2014; Tsai et al., 2009).

Positive and statically significant associations between PDs and IA were also observed, specifically, for Narcissistic, Borderline, Obsessive-compulsive, Schizotypal, Antisocial, Avoidant, Dependent, and Schizoid PDs. When compared by sex, differences were observed in the associations with some PDs, with men presenting more comorbidity with Schizoid, Schizotypal and Antisocial PDs. The most investigated PD in the studies was Borderline, showing no differences in relation to sex, and showing the highest prevalence, possibly being the PD most related to IA. According to Floros et al. (2014), patients diagnosed with Borderline PD are those who should present greater exacerbation in IA behaviors.

We can conclude that there is relationship between IA and pathological personality traits, i.e., people who present high scores in specific personality traits tend to show typical behaviors of IA (Bernardi \& Pallanti, 2009; Dalbudak et al., 2014, Floros et al., 2014). These findings can bring some possibilities to the clinical context. For instance, if the patient shows behaviors related to IA, the clinician can use this information as an indicator of the presence of pathological traits. The inverse can also be true, although personality traits are probably before the development of specific addictions. Considering these implications, future studies should focus on the occurrence of IA in patients diagnosed with PD.

One should observe that associations between IA and pathological personality traits may be more expressive than what we found, since most studies did not use clinical samples or samples with patients diagnosed with PDs. There is a tendency for low responses (disagreement of items) and decreased variability of responses in instruments using samples from the general population, therefore, results may be different for clinical samples.

The main limitations of this research should be observed. The first limitation refers to the non-use of gray literature (e.g., unpublished studies, thesis, dissertations); we did not perform a meta-analysis of the results regarding IA; and for the data related to IA, we did not perform a new search in the literature, as we were already using IA as a descriptor. Besides, our review was focused on only one online social network, the Facebook. Although it's currently the most popular social network, not including other platforms could bring some limitations to our findings.

Based on the objective of this systematic review, we can hypothesize that the present results can be generalized for Facebook use, since a significant part of the internet use can be explained by the use of this SNS (Poli, 2017). However, some reservations should be outlined, for instance, the definitions for the constructs involved. More research is required to investigate similarities and differences between Internet addiction and Facebook PU.

\section{References}

\section{* denotes a reference among the reviewed studies}

Abhijit N. (2012). Facebook Addiction. USA: Buzzle. Resource document. http://www.buzzle.com/articles/facebook-addiction.html

American Psychiatric Association. (2013). Diagnostic and Statistical Manual of Mental Disorders. Arlington, VA: American Psychiatric Association.

Andreassen, C. S. (2015). Online Social Network Site Addiction: A comprehensive review. Current Addiction Reports, 2(2), 175-184. doi: 0.1007/ s40429-015-0056-9

Andreassen, C. S., Torsheim, T., Brunborg, G. S., \& Pallesen, S. (2012). Development of a Facebook addiction scale. Psychological Reports, 110(2), 501-17. doi: 10.2466/02.09.18.PR0.110.2.501-517.

Belin, D., Mar, A. C., Dalley, J. W., Robbins, T. W., \& Everitt, B. J. (2008). High impulsivity predicts the switch to compulsive cocaine taking. Science, 320(5881), 1352-1355. doi: 10.1126/science. 1158136 
*Bernardi, S. \& Pallanti, S. (2009). Internet addiction: a descriptive clinical study focusing on comorbidities and dissociative symptoms. Comprehensive Psychiatry, 50(6), 510-516. doi: 10.1016/j. comppsych.2008.11.011.

Blachnio, A., Przepiorka, A., Senol-Durak, E., Durak, M., \& Sherstyuk, L. (2017). The role of personality traits in Facebook and Internet addictions: A study on Polish, Turkish, and Ukrainian samples. Computer in Human Behavior, 30(2), 149-155. doi: 10.1016/j.chb.2016.11.037

Block, J. J. (2008). Issues of DSM-V: Internet Addiction. The American Journal of Psychiatry, 165(3), 306-307. doi: 10.1176/appi.ajp.2007.07101556

Butt, S., \& Phillips, J. G. (2008). Personality and self-reported mobile phone use. Computer in $\mathrm{Hu}$ man Behavior, 24(2), 346-360. doi: 10.1016/j. chb.2007.01.019

*Chang, W., Cheng, S., Sun, Z., Lee, I., Lee, C., Chen, K., Tsai, C., Yang, Y., \& Yang, Y. (2015). The psychosocial indicators related to neuroticism in both sexes: A study of incoming university students. Kaoshiung Jounal of Medical Sciences, 31(4), 208-14. doi: 10.1016/j.kjms.2014.12.009

*Dalbudak, E., Evren, C., Topcu, M., Aldemir, S., Coskun, K. S., Bozkurt, M., Evren, B., \& Canbal, M. (2013). Relationship of internet addiction with impulsivity and severity of psychopathology among Turkish university students. Psychiatry Research, 210(3), 1086-1091. doi: 10.1016/j. psychres.2013.08.014

Dalbudak, E., \& Evren, C. (2014). The relationship of Internet addiction severity with Attention Deficit Hyperactivity Disorder symptoms in Turkish University students; impact of personality traits, depression and anxiety. Comprehensive Psychiatry, 55(3), 497-503. doi: 10.1016/j.comppsych.2013.11.018

*Dalbudak, E., Evren, C., Aldemir, S., \& Evren, B. (2014). The severity of internet addiction risk and its relationship with severity of borderline personality features, childhood traumas, dissociative experiences, depression and anxiety symptoms among Turkish University Students. Psychiatry Research, 219(3), 577-582. doi: 10.1016/j. psychres.2014.02.032

*Dong, G., Wang, J., Yang, X., \& Zhou, H. (2012). Risk personality traits of Internet addiction: a longitudinal study of Internet-addicted Chinese university students. Asia Pac Psychiatry, 5(4). doi: 10.1111/j.1758-5872.2012.00185.x

Elphinston, R. A., \& Noller, P. (2011). Time to face it! Facebook intrusion and the implications for romantic jealousy and relationship satisfaction. Cyberpsychology, Behavior and Social Networking, 14(11), 631-5. doi: 10.1089/cyber.2010.0318.

*Floros, G., Siomos, K., Stogiannidou, A., Giouzepas, I., \& Garyfallos, G. (2014). Comorbidity of psychiatric disorders with Internet addiction in a clinical sample: The effect of personality, defense style and psychopathology. Addictive Behaviors, 39(12), 1839-1845. doi: 10.1016/j.addbeh.2014.07.031

Ginige, P. (2017). Internet Addiction Disorder. In Maurer, M. H. (Ed.), Child and adolescent mental health. doi: 10.5772/66966

Greenfield, D. N. (1999). Psychological characteristics of compulsive internet use: a preliminary analysis. Cyberpsychology \& Behavior, 2(5), 403-12. doi: 10.1089/cpb.1999.2.403

Grifths, M. (2013). Social gambling via Facebook: further observations and concerns. Gaming Law Review and Economics, 17(2), 104-106. doi: 10.1089/ glre.2013.1726

Griffiths, M. D., Kuss, D. J., \& Demetrovics, Z. (2014). Social networking addiction: an overview of preliminary findings. In K. P. Rosenberg, \& L. Curtiss Feder (Eds.), Behavioral addictions: Criteria, evidence, and treatment (pp. 119-141). San Diego, CA, US: Elsevier Academic Press.

Guedes, E., Nardi, A. E., Guimarães, F. M., Machado, S., \& King, S. (2016). Social Networking, a new online addiction: a review of Facebook and other addiction disorders. Medical Express, 3(1). doi: 10.5935/MedicalExpress.2016.01.01

Hofmann, W., Vohs, K. D., \& Baumeister, R. F. (2012). What people desire, feel conflicted about, and try to resist in everyday life. Psychol Sci, 23(6), 582-8. doi: 10.1177/0956797612437426

Kapidzic, S. (2013). Narcissism as a Predictor of Motivations Behind Facebook Profile Picture Selection. Cyberpsychology Behavior and Social Networking, 16(1), 14-9. doi: 10.1089/cyber.2012.0143

*Laconi, A., Andréoletti, A., Chauchard, E., Rodgers, R. F., \& Chabrol, H. (2016). Problematic Psico-USF, Bragança Paulista, v. 26, n. 3, p. 451-465, jul./set. 2021 
internet use, time spent online and personality traits. L'Encephala, 42(3), 214-218. doi: 10.1016/j. encep.2015.12.017

Lang, A., Edwards, N., \& Fleiszer, A. (2007). Safety in home care: a broadened perspective of patient safety. International Journal for Quality in Health Care, 20(2), 130-135. doi: 10.1093/intqhc/mzm068

Lee, Z. W. Y., Cheung, C. M. K., \& Thadani, D. R. (2012). An investigation into the Problematic Use of $\mathrm{Fa}^{-}$ cebook. 45th Hawaii International Conference on System Sciences doi: 10.1109/HICSS.2012.106

Mahajan, P. (2009). Use of social networking in a linguistically and culturally rich India. International Information and Library Review, 41(3), 129-136. doi: 10.1016/j.iilr.2009.07.004

Marino, C., Vieno, A., Moss, A. C., Caselli, G., Nikcevic, A. V., \& Spada, M. M. (2016). Personality, motives and metacognitions as predictors of problematic Facebook Use in university students. Personality and Individual Differences, 101, 70-77. doi: 10.1016/j. paid.2016.05.053

Mazhari, S. (2012). Association between problematic internet use and impulse control disorders among Iranian university students. Cyberpsychology, Behavior, and Social Networking, 15(5). doi: 10.1089/ cyber.2011.0548

McCrae, R. R., Costa, P. T., Terracciano, A., Parker, W. D., Mills, C. J., De Fruyt, F., \& Mervielde, I. (2002). Personality trait development from age 12 to age 18: Longitudinal, cross-sectional and cross analyses. Journal of Personality and Social Psychology, 83(6), 1456-68. doi: 10.1037/0022-3514.83.6.1456

Mehdizadeh, S. (2010). Self-Presentation 2.0: Narcissism and self-esteem on Facebook. Cyberpsychology, Behavior and Social Networking, 13(4), 357-64. doi: 10.1089=cyber.2009.0257

Moat, K. A., Lavis, J. N., Wilson, M. G., Rottingen, J., \& Bärnighausen, T. (2013). Twelve myths about systematic reviews for health system policymaking rebutted. Journal of Health Services Research \& Policy, 18(1), 44-50. doi: 10.1258/jhsrp.2012.011175

Moher, D., Liberati, A., Tetlaff, J., \& Altman, D. G. (2009). Preferred Reporting Items for Systematic Reviews and Meta-Analyses: The PRISMA Statement. PLoS Med, 6(7). doi: 10.1371/journal. pmed.1000097
Mok, J-Y., Choi, S-W., Kim, D-J., Choi, J-S., Lee, J., Ahn, H., Choi, E-J., \& Song, W-Y. (2014). Latent class analysis on internet and smartphone addiction in college students. Neuropsychiatric Disease and Treatment, 10, 817-828. doi: 10.2147/NDT.S59293

Moons, K. G. M., Groot, J. A. H., Bouwmeester, W., Vergouwe, Y., Mallett, S., Altman, D., Reitsma, J., \& Collins, G. S. (2014). Critical Appraisal and Data Extraction for Systematic Reviews of Prediction Modelling Studies: The CHARMS Checklist. PLoS Med, 11(10), e1001744. doi: 10.1371/journal. pmed.1001744

*Mottram, A. J., Fleming, M. J. (2009). Extraversion, Impulsivity, and Online Group Membership as Predictors of Problematic Internet use. CyberPsychology \& Behavior, 12(3), 319-21. doi: 10.1089/ cpb.2007.0170

*Müller, K. W., Koch, A., Dickenhorst, U., Beutel, M. E., Duven, E., \& Wölfling, K. (2013). Addressing the Question of Disorder-Specfic Risk Factors of Internet Addiction: A Comparison of Personality Thaits in Patients with Addictive Behaviors and Comorbid Internet Addiction. BioMed Research International. doi: 10.1155/2013/546342

Onnela, J. P., \& Rauch, S. L. (2016). Harnessing Smartphone-Based Digital Phenotyping to Enhance Behavioral and Mental Health. Neuropsychopharmacology, 41(7). doi: 10.1038/npp.2016.7

Poli (2017). Internet addiction update: diagnostic criteria, assessment and prevalence. Mental Health Department of Cremona Hospital, 7(1), 04-08. doi: 10.4172/Neuropsychiatry.100017

Rosen, L. D., Whaling, K., Rab, S., Carrier, L. M. Cheever, N. A. (2013). Is Facebook creatring "iDisorders"? The link between clinical symptoms of psyquiatric disorders and technology use, attitudes and anxiety. Computers in Human Behavior, 29(3), 1243-1254. doi: 10.1016/j.chb.2012.11.012

Schlosser, R. W., \& Sigafoos, J. (2009). 'Empty' reviews and evidence-based practice. Psychology Press, 3(1), 1-3. doi: 10.1080/17489530902801067

*Senormanci, O., Saraçli, O., Atasoy, N., Senormanci, G., Koktürk, F., \& Atik, L. (2014). Relationship of Internet addiction with cognitive style, personality, and depression in university students. Comprehensive Psychiatry, 55(6), 1385-1390. doi: 10.1016/j. comppsych.2014.04.025 
Slyer, J. T. (2016). Unanswered questions: implications of an empty review. JBI Database of Systematic Reviews and Implementation Reportss, 14(6), 1-2. doi: 10.11124/JBISRIR-2016-002934

*Tsai, H. F., Cheng, S. H., Yeh, T. L., Shih, C. C., Chen, K. C., Yang, Y. C., et al. (2009). The risk factors of Internet addiction--a survey of university freshmen. Psychiatry Research, 167(3), 294-299. doi: 10.1016/j.psychres.2008.01.015

von Elm, E., Altman, D. G., Egger, M., Pocock, S. J., Gøtzsche, P. C., Vandenbroucke, J. P., et al. (2007). Strengthening the Reporting of Observational Studies in Epidemiology (STROBE) statement: guidelines for reporting observational studies. BMJ, 335(7624), 806-808. doi: 10.1136/ bmj.39335.541782.AD

Wölfling, K., Beutel, M. E., Dreier, M., \& Müller, L. W. (2015). Bipolar spectrum disorders in a clinical sample of patients with Internet addiction: Hidden comorbidity or differential diagnosis? Journal of Behavioral Addictions, 4(2), 101-105. doi: 10.1556/2006.4.2015.011

*Wu, J. Y., Ko, H., \& Lane, H. (2016). Personality Disorders in Female and Male College Students with Internet Addiction. The Journal of Nervous and Mental Disease, 204(3). doi: 10.1097/ NMD.0000000000000452

*Wu, J., Ko, H., Tung, Y., \& Li., C. (2016). Internet use expectancy for tension reduction and disinhibition mediates the relationship between borderline personality disorder features and Internet addiction among college students - One-year follow-up. Computers in Human Behavior, 55(B), 851-855. doi: 10.1016/j.chb.2015.09.047

Yaffe, J., Montgomery, P., Hopewell, S., \& Shepard, L. D. (2012). Empty Reviews: A Description and Consideration of Cochrane Systematic Reviews with No Included Studies. PLOS ONE, 7(5), e366626. doi: 10.1371/journal.pone.0036626

*Yen, J. Y., Ko, C. H., Yen, C. F., Chen, C. S., \& Chen, C. C. (2009). The association between harmful alcohol use and Internet addiction among college students: comparison of personality. Psychiatry and Clinical Neurosciences, 9(2), 97. doi: 10.1111/j.1440-1819.2009.01943.x.

Young, K.S. (1996). Psychology of computer use: XL. Addictive use of the Internet: a case that breaks the stereotype. Psychological Reports, 79, 899-902.

Young, K. S. (1998). Internet addiction: the emergence of a new clinical disorder. Cyberpsychology, Behavior, and Social Networking, 1(3). doi: 10.1089/ cpb.1998.1.237

*Zadra, S., Bischof, G., Besser, B., Bischof, A., Meyer, C., John, U., \& Rumpf, H. (2016). The association between Internet addiction and personality disorders in a general population-based sample. Journal of behavior addictions, 5(4), 691-699. doi: $10.1556 / 2016.08$

Recebido em: 26/06/2019

Reformulado em: 27/06/2020

Aprovado em: 17/08/2020 
About the authors:

Bárbara Letícia Ferrari é psicóloga pela Universidade São Francisco (USF) e Mestre em Psicologia pela mesma instituição.

ORCID: https://orcid.org/0000-0001-9127-9972

E-mail: blf.ferrari@gmail.com

Lucas de Francisco Carvalho é Docente do Programa de Pós-Graduação Stricto Sensu em Psicologia da Universidade São Francisco (USF)

ORCID: https://orcid.org/0000-0002-3274-9724

E-mail: lucas@labape.com.br

Catarina Possenti Sette é psicóloga pela Universidade São Francisco (USF) e Mestre e Doutora em Psicologia pela mesma instituição; Coordenadora de Projetos no Instituto Ayrton Senna.

ORCID: https://orcid.org/0000-0001-6285-0826

E-mail: catarinasette@hotmail.com

Contact:

Universidade São Francisco, Programa de Pós-graduação em Psicologia

Rua Waldemar César da Silveira, 105

Campinas-SP, Brazil

CEP: $13045-510$

Phone: (55 19) 3779-3300

Psico-USF, Bragança Paulista, v. 26, n. 3, p. 451-465, jul./set. 2021 
